\title{
STABILITY AND CHANGE IN POLITICAL ATTITUDES: Observed, Recalled, and "Explained"
}

\author{
Gregory B. Markus
}

\begin{abstract}
Using data from a panel survey of members of two generations, this study explores observed change in policy opinions across a 9-year span and respondents' recollections and explanations of their self-perceived attitude shifts. In general, remembrances corresponded poorly to opinions as originally expressed, with respondents perceiving that they were more attitudinally stable than was actually observed. When attempting to reconstruct their past political attitudes, individuals appeared to rely on simple rules of thumb such as one might employ to account for another's behavior. Finally, respondents readily supplied "explanations" for their self-perceived attitude history, even when those perceptions directly contradicted observed opinion change. It is argued that these results are not artifacts of survey measurement problems. Instead, they indicate that policy attitudes generally do not have strong cognitive representations, are eminently changeable, and once they are changed, an individual's cognitive autobiography is revised so as to render the changes invisible.
\end{abstract}

It is commonplace in both survey research and everyday life to be prompted to think about one's attitude on some topic and, perhaps, to recall the history behind that attitude. There is some evidence that under many conditions "individuals come to 'know' their own attitudes, emotions, and other internal states partially by inferring them from the observation of their own overt behavior and/or the circumstances in which this behavior occurs" (Bem, 1972, p. 2). That is to say, the introspective processes employed to cognize one's own attitudes may not be very different from those that are used to infer the attitudes of others. Nisbett and Wilson (1977) argued, for example, that when people are asked to report the cognitive processes they themselves used to reach a particular judgment,

Gregory B. Markus, Center for Political Studies, University of Michigan.

Political Behavior

(C) 1986 Agathon Press, Inc.

Vol. 8 , No. 1 
they resort to the same kinds of rules of thumb ("a priori, implicit causal theories") that they would use to account for another's behavior. Results such as these suggest that we may legitimately question whether individuals are any more privy to their own attitudes or the processes culminating in those attitudes than are external observers.

The present study begins by recording the correspondence between individuals' opinions on social and political issues of national scope as observed at two widely separated points in their adult lives. Using these observed patterns of attitude change as a point of departure, the investigation then considers individuals' perceptions of their own attitude developments during the period under study. To what extent do individuals' recollections of their earlier opinions diverge from those opinions as originally stated? Are such divergences essentially chaotic; that is, do memories of past attitudes become progressively fuzzed by random noise as time goes by? Or, alternatively, are there systematic, predictable tendencies in the ways that people reconstruct their attitudinal autobiographies - tendencies that are consistent with results obtained in experimental settings by Bem, Nisbett and Wilson, and others? Finally, for those individuals who believe that their social and political views have changed, what kinds of causal explanations of those changes do they provide?

The investigation makes use of data from a national survey of individuals interviewed in 1973 and again in 1982. The survey respondents are members of two biologically linked generations, one made up of persons who entered adulthood during the politically turbulent era of the late 1960s and the other consisting of their parents.

The focus of this report is individual political cognition, and the interpretation of the empirical results that follow borrows heavily from experimental research in cognitive psychology. Nevertheless, the extent to which people possess coherent, predictable political opinions, or believe they possess such opinions, is of importance to political scientists. Perhaps most obviously, evidence that individuals are unreliable witnesses to their own attitude change would undermine our confidence in surveys that ask people to recall or explain their political views (see Moss and Goldstein, 1979; Smith, 1984; Smith and Klaeser, 1983). More important, if individuals can (and do) readily rewrite their cognitive autobiographies so as to support the belief that they have always held their present opinions, this can have direct macropolitical ramifications. Orwell's 1984 is the best-known portrayal of some of these ramifications (cf., Greenwald, 1980), but equally dramatic examples can be drawn from real life political "re-education" schemes (see, e.g., Fagen, 1964/1970). 


\section{DATA BASE}

This study makes use of information gathered in the last two waves of what is, at least so far, a 17-year, three-wave panel survey. The panel study began in 1965 as an investigation of the political orientations of American adolescents and their parents. A national sample of high school seniors of the graduating class of 1965 was drawn, and 1,669 of them, along with at least one parent in nearly every case, were personally interviewed (Jennings and Niemi, 1974). A follow-up survey of the original respondents in both generations occurred in 1973 (Jennings and Niemi, 1981), and a third wave of interviews took place in the summer of 1982 (Jennings and Markus, 1984).

Complete three-wave data exist for 898 parents $(57 \%$ of the original sample, or $64 \%$ of those still living as of 1982) and for 1,135 offspring $(68 \%$ retention, or $70 \%$ excluding deceased). Preliminary analysis indicates no obvious biases introduced by selective panel mortality for either generation (Jennings and Markus, 1984). Even so, it should be kept in mind that the samples are not entirely representative of their broader age cohorts. By definition, the younger respondents all possess at least a high school education. Similarly, the parental respondents were defined by the presence of a high school senior in the household in 1965. But any difficulty the special character of these samples may create in generalizing to national populations is more than compensated by the durability and longevity of the panels - and by certain unique items that were included in the questionnaires.

The last point is especially relevant to this study's mission. The second wave (1973) interview schedule adapted a set of items that had been developed for the 1968 Center for Political Studies' National Election Survey. Those items invited respondents to locate their preferred policy positions on a series of labeled 7-point continua referring to various issues of the day: domestic social welfare spending, affirmative action for minorities, marijuana legalization, and so on. A similar type of scale was employed to determine respondents' general conceptions of their ideological points of view, from extreme liberal to extreme conservative. In every instance, persons who "haven't thought much about" a given topic were given an opportunity to sidestep the question gracefully.

This methodology was repeated in the 1982 wave for the four topics mentioned above plus equal rights for women and protecting the legal rights of persons accused of crimes, two issues also covered previously in the 1973 interviews. Beyond this, respondents in 1982 were requested to 
recall what their positions on these matters were in 1973. And those who believed that their opinions had changed in the interim were asked if they had any explanation for why their views had changed. It is these data from the 1973 and 1982 waves that provide the basis of the present investigation.

\section{RESULTS}

\section{Observed Change in Stated Attitudes, 1973 to 1982}

As a source of information on long-term attitude change, the data base described above is unique in terms of the sample size and the duration of the study. That the data capture the social and political outlooks of the historically significant "Vietnam era" or "baby-boom" generation makes them all the more noteworthy. For these reasons, before delving into the psychological processes underlying recall and explanation of ones attitude development, it is worth while first simply to document the degree of manifest stability and change in respondents' policy preferences as stated initially in 1973 and subsequently in 1982.

The best place to begin is by noting that most respondents were willing to state preferred positions on the five policy items in both interviews. "Haven't thought much" responses among the young adults in 1973 ranged from $2 \%$ (women's rights) to $9 \%$ (government job guarantees); for that same cohort in 1982, those rates remained essentially constant. Probably owing to their lower overall education levels, proportionately more of their parents declined to locate themselves on the five issue continua in each wave-from $5 \%$ to $12 \%$, depending on the issue. As expected from the experiences of other survey studies, relatively more respondents preferred to bypass the ideological placement question. On both occasions $14 \%$ of the younger respondents opted out of that item, while $23 \%$ and $25 \%$ of their parents did so in 1973 and 1982 , respectively.

\section{Aggregate Attitude Distributions}

As Table 1 shows, in 1973 the baby-boom cohort was consistently more liberal than were their parents as a group on all five policy items and on overall ideological self-concept. With the exception of the women's role issue, there was a slight conservative drift for the parents from 1973 to 1982 and a more noticeable one for the offspring. Whether those shifts were agerelated or else due to the prevailing sociopolitical context of the period is the subject of another study, but either way the net result was a considerable narrowing of the generation gap. ${ }^{1}$ In 1982 the offspring remained somewhat more liberal than their parents on protecting the rights of the 
TABLE 1. Aggregate Profiles of Issue Positions as Stated in 1973 and 1982

A. Government guaranteed jobs and living standard versus let people get ahead on their own.

\begin{tabular}{lrrrrrrr} 
& $\begin{array}{c}\text { Government } \\
\text { Guarantee } \\
(1-2)\end{array}$ & 3 & 4 & 5 & $\begin{array}{c}\text { Ahead } \\
\text { on Own } \\
(6-7)\end{array}$ & \multicolumn{2}{c}{ Total } \\
\hline Parents, 1973 & $10 \%$ & 8 & 27 & 17 & 37 & $99 \%$ & $(797)$ \\
Parents, 1982 & $9 \%$ & 8 & 28 & 22 & 34 & $101 \%$ & $(781)$ \\
Offspring, 1973 & $15 \%$ & 14 & 25 & 20 & 26 & $100 \%(1,032)$ \\
Offspring, 1982 & $8 \%$ & 10 & 20 & 28 & 35 & $101 \%(1,065)$ \\
\hline
\end{tabular}

B. Protect the rights of those accused of crimes versus stop crime even at risk of reducing rights.

\begin{tabular}{lcrccccc} 
Respondents & $\begin{array}{c}\text { Protect } \\
\text { Rights } \\
(1-2)\end{array}$ & 3 & 4 & 5 & $\begin{array}{c}\text { Crime } \\
(6-7)\end{array}$ & \multicolumn{1}{c}{ Total } \\
\hline Parents, 1973 & $22 \%$ & 8 & 21 & 13 & 36 & $100 \%$ & $(791)$ \\
Parents, 1982 & $12 \%$ & 7 & 18 & 19 & 45 & $101 \%$ & $(791)$ \\
Offspring, 1973 & $39 \%$ & 14 & 19 & 13 & 15 & $99 \%(1,071)$ \\
Offspring, 1982 & $15 \%$ & 9 & 22 & 23 & 31 & $100 \%(1,090)$ \\
\hline
\end{tabular}

C. Government help for minority groups versus minority groups should help themselves.

\begin{tabular}{lcrrrrrr} 
& $\begin{array}{c}\text { Government } \\
\text { Help } \\
\text { Respondents }\end{array}$ & $(1-2)$ & 3 & 4 & 5 & $\begin{array}{c}\text { Thelp } \\
(6-7)\end{array}$ & \multicolumn{2}{c}{ Total } \\
\hline Parents, 1973 & $17 \%$ & 7 & 33 & 11 & 32 & $100 \%$ & $(833)$ \\
Parents, 1982 & $11 \%$ & 9 & 29 & 17 & 33 & $99 \%$ & $(822)$ \\
Offspring, 1973 & $25 \%$ & 17 & 24 & 16 & 18 & $100 \%(1,087)$ \\
Offspring, 1982 & $12 \%$ & 13 & 25 & 21 & 29 & $100 \%$ & $(1,094)$ \\
\hline
\end{tabular}

D. Legalize marijuana use versus set penalties higher.

\begin{tabular}{|c|c|c|c|c|c|c|}
\hline Respondents & $\begin{array}{c}\text { Legalize } \\
\text { Use } \\
(1-2)\end{array}$ & 3 & 4 & 5 & $\begin{array}{c}\text { Higher } \\
\text { Penalties } \\
(6-7)\end{array}$ & Total \\
\hline Parents, 1973 & $9 \%$ & 4 & 14 & 7 & 66 & $100 \%$ \\
\hline Parents, 1982 & $10 \%$ & 2 & 11 & 7 & 69 & $99 \% \quad(795)$ \\
\hline Offspring, 1973 & $31 \%$ & 10 & 16 & 6 & 36 & $99 \%(1,087)$ \\
\hline Offspring, 1982 & $24 \%$ & 9 & 20 & 8 & 39 & $100 \%(1,072)$ \\
\hline
\end{tabular}


TABLE 1. (Continued)

E. Women and men should have equal roles versus women's place is in the home.

\begin{tabular}{lcrrrrrr} 
& $\begin{array}{c}\text { Equal } \\
\text { Roles } \\
(1-2)\end{array}$ & \multicolumn{1}{c}{ Respondents } & 4 & 5 & $\begin{array}{c}\text { Home } \\
(6-7)\end{array}$ & \multicolumn{1}{c}{ Total } \\
\hline Parents, 1973 & $29 \%$ & 7 & 28 & 11 & 26 & $100 \%$ & $(849)$ \\
Parents, 1982 & $43 \%$ & 7 & 22 & 9 & 18 & $99 \%$ & $(846)$ \\
Offspring, 1973 & $49 \%$ & 12 & 19 & 8 & 13 & $101 \%(1,115)$ \\
Offspring, 1982 & $68 \%$ & 9 & 12 & 4 & 6 & $99 \%(1,118)$ \\
\hline
\end{tabular}

F. Liberal political views versus conservative political views.

\begin{tabular}{lccccccc} 
& Liberal & \multicolumn{5}{c}{ Conservative } \\
Respondents & $(1-2)$ & 3 & 4 & 5 & $(6-7)$ & \multicolumn{2}{c}{ Total } \\
\hline Parents, 1973 & $10 \%$ & 7 & 38 & 25 & 20 & $100 \%$ & $(692)$ \\
Parents, 1982 & $9 \%$ & 6 & 38 & 22 & 25 & $100 \%$ & $(668)$ \\
Offspring, 1973 & $17 \%$ & 23 & 32 & 17 & 11 & $100 \%$ & $(978)$ \\
Offspring, 1982 & $12 \%$ & 16 & 29 & 25 & 18 & $100 \%$ & $(977)$ \\
\hline
\end{tabular}

Note. Percentages are based on individuals interviewed in both waves. Percentages may not sum to 100 due to rounding.

accused, marijuana legalization, and overall ideological posture, but on two other issues, government job guarantees and aid to minorities, the 1982 generational contrasts were negligible. Contrary to the general conservative trend, both generations were markedly more positive toward equality in gender roles in 1982 than they were 9 years earlier; because both age groups moved leftward in the aggregate by roughly equal amounts on this issue, the offspring remained more liberal than their parents.

\section{Individual Level Stability}

The generally placid aggregate profiles of parents' opinions are no guarantee of attitude stability at the individual level. Indeed, Converse's (1964, 1970 ) original work on "nonattitudes" was spurred by the observation that opinion turnover tables from panel surveys often displayed roughly constant marginals coexisting with heavy, but countervailing, circulation of respondents among opinion categories. Consequently, it is important to consider individual-level as well as net change.

As shown in Table 2, our respondents exhibited a fair amount of mani- 
TABLE 2. Correspondence between Individuals' Issue Positions as Stated in 1973 and 1982

\begin{tabular}{|c|c|c|c|}
\hline Issue & Correlation $^{a}$ & $\begin{array}{c}\text { Same } \\
\text { Position } \\
\text { (percentage) }\end{array}$ & $\begin{array}{c}\text { Difference of } \\
3+\text { Categories } \\
\text { (percentage) }\end{array}$ \\
\hline \multicolumn{4}{|c|}{ Parents } \\
\hline Guaranteed jobs & .41 & 32 & 16 \\
\hline Rights of accused & .29 & 26 & 28 \\
\hline Aid to minorities & .37 & 29 & 21 \\
\hline Legalize marijuana & .43 & 50 & 22 \\
\hline Women's roles & .44 & 33 & 30 \\
\hline Ideology & .57 & 48 & 4 \\
\hline \multicolumn{4}{|c|}{ Offspring } \\
\hline Guaranteed jobs & .35 & 27 & 18 \\
\hline Rights of accused & .32 & 22 & 29 \\
\hline Aid to minorities & .41 & 27 & 20 \\
\hline Legalize marijuana & .61 & 36 & 22 \\
\hline Women's roles & .44 & 37 & 22 \\
\hline Ideology & .45 & 35 & 9 \\
\hline
\end{tabular}

${ }^{u}$ Entries are Pearson product-moment correlations.

fest instability in individual attitudes from one wave of interviewing to the next. Although the baby-boomers experienced a relatively larger net attitude shift, they were not appreciably more unstable at the individual level than were their parents from 1973 to 1982 . That is, parents were only slightly more likely than their offspring to express identical opinions in both surveys, and across all six items the two cohorts were about equal in terms of the proportions of individuals who shifted stated positions by three or more points from one wave to the next.

Another perspective on individual change is offered by the continuity correlations in Table 2. Those coefficients measure relative stability, i.e., the extent to which individuals maintained the same relative positions in their cohort's distribution of policy preferences apart from any uniform shifts of opinion that may have occurred. In terms of relative stability, the two cohorts were once again generally comparable, a result that coincides with that obtained with respect to other political and nonpolitical orientations of these panel members (Jennings and Markus, 1984).

Before leaving Table 2, there is one other observation worth making. A previous study using materials from the 1956-58-60 and 1972-74-76 National Election Study panel surveys uncovered a rough hierarchy in the 
temporal stability of individual attitudes toward various issue domains (Converse and Markus, 1979). In general, opinions on issues associated with personal moral values tended to be the most stable (as indexed by autocorrelation values) followed by domestic issues having concrete, uncomplicated referents, e.g., government guaranteed jobs or federal enforcement of school integration. Bringing up the rear in terms of relative stability were attitudes toward matters remote from everyday experience or that dealt with abstract political themes, such as foreign policy or whether the federal government has become too powerful. The patterns of correlations in Table 2 are entirely in keeping with the NES results: of the five issue areas covered in the present surveys, attitudes toward marijuana legalization and equality of gender roles were the most stable within each cohort, responses to the items concerning domestic jobs programs and government aid to minority groups came next, and opinions regarding legal guarantees of the rights of defendants displayed the lowest correlations.

As occurred in the Converse-Markus NES analysis, the relative stability of ideological self-concept rivaled that of opinions on morally charged issues. The explanation for this result is contained in the special circumstances surrounding responses to the ideology item. First, a large chunk of the total population was eliminated entirely from the computation of stability measures by the "no opinion" filter. Among the parents, fully $35 \%$ failed to locate themselves on a liberal-conservative continuum in at least one wave of interviews; and even among their more highly educated offspring, 23\% passed the item by in either 1973 or 1982 . Second, of those persons who did respond, as many as one in five chose to play it safe by selecting each time the center location (which is also virtually the mean of the distribution), thereby neither adding to nor detracting from correlation values. It is, therefore, technically correct that ideological self-concept was fairly enduring, but the fine print states that this conclusion applies only to a decidedly select population.

\section{Recollections of Political Attitudes}

The 1982 interviews elicited not only respondents' current political orientations but also their recollections of what their orientations had been 9 years earlier. There is good reason to expect that those recollections would not be particularly accurate, in the sense of corresponding to opinions as recorded in 1973. In the lingo of cognitive psychology, policy preferences ordinarily lack clear internal representations: they are only glancingly related to one's sense of self identity ("self-schema") and are typically not linked to readily available memories of salient events or experiences (cf., 
TABLE 3. Correspondence between 1973 Stated Issue Positions and Those Positions as Recalled in 1982

\begin{tabular}{|c|c|c|c|}
\hline Issue & Correlation $^{s}$ & $\begin{array}{c}\text { No } \\
\text { Difference } \\
\text { (percentage) }\end{array}$ & $\begin{array}{c}\text { Difference of } \\
3+\text { Categories } \\
\text { (percentage) }\end{array}$ \\
\hline \multicolumn{4}{|c|}{ Parents } \\
\hline Guaranteed jobs & .40 & 30 & 19 \\
\hline Rights of accused & .29 & 27 & 29 \\
\hline Aid to minorities & .34 & 27 & 22 \\
\hline Legalize marijuana & .31 & 47 & 20 \\
\hline Women's roles & .39 & 30 & 30 \\
\hline Ideology & .56 & 43 & 4 \\
\hline \multicolumn{4}{|c|}{ Offspring } \\
\hline Guaranteed jobs & .33 & 25 & 20 \\
\hline Rights of accused & .33 & 24 & 25 \\
\hline Aid to minorities & .38 & 24 & 21 \\
\hline Legalize marijuana & .60 & 35 & 20 \\
\hline Women's roles & .40 & 33 & 24 \\
\hline Ideology & .56 & 36 & 6 \\
\hline
\end{tabular}

${ }^{a}$ Entries are Pearson product-moment correlations.

Markus and Zajonc, 1985; Fiske and Taylor, 1984). For most people, then, to recall a policy opinion is a mental exercise that "may be impossible and undoubtedly is difficult" (Smith, 1984, p. 645). Indeed, if 30 years of survey research has determined anything, it is that for most people most of the time political policy matters are remote from daily concerns, and it is quite enough for citizens to provide interviewers with some sense of what their current issue attitudes are, let alone recall what their dispositions might have been many years ago (see, e.g., Kinder and Sears, 1985).

Whether or not it is entirely fair to ask respondents to dredge up political predispositions from 9 years previous, they were apparently willing to try. Among those persons who provided a current self-placement in 1982, only $2 \%$ to $6 \%$ (depending on the topic) declined the added invitation to estimate where they stood on the various policy and ideological continua in 1973. Their efforts were only modestly successful, however, as evidenced by Table 3. On average, only about one-third of respondents' 1982 recollections coincided with their 1973 self-placements; and depending on the cohort and the topic, the proportion of recollections that diverged from originally stated positions by 3 or more points on a 7 -point continuum was often as large as or even larger than the proportion that matched. 
Beyond the verification of suspicions of modest recollective reliability lay some questions with less foregone answers. To reiterate the introductory remarks, one such question concerns whether divergences between recalled and originally stated attitudes consist of little more than random noise or whether instead there are systematic heuristics that individuals employ when reconstructing their cognitive autobiographies. There is reason to believe that the latter is true.

A standard manipulation employed is experimental studies of attitude change involves asking subjects to engage in some particular counterattitudinal behavior and then observing the extent to which their attitudes subsequently change in the hypothesized direction. In one such experiment (involving counterattitudinal essay writing), Bem and McConnell (1970) examined not only whether attitude change occurred but also whether subjects were aware that their attitudes had changed. As part of the postmanipulation measurement, the experimenters asked subjects what their attitudes had been one week earlier, prior to the experimental treatment. Control subjects who wrote no essays did not change attitudinally and were fairly accurate in reporting as much. In contrast, though the postmanipulation attitudes of experimental subjects differed substantially and systematically from their attitudes as stated prior to the experiment, those subjects also reported that their previous attitudes were the same as their current ones. As Bem and McConnell put it, "actual premanipulation attitudes are not salient features of postmanipulation phenomenology and are recalled as identical to postmanipulation attitudes" (p. 28).

A similar result was obtained by Goethals and Reckman (1973), even though the participants in their study were explicitly reminded that the experimenters had retained participants' premanipulation opinion statements and would be checking the accuracy of their recall. Again, the suggestion is that individuals may undergo attitude change without being aware that such a process has occurred. To account for results such as these, Bem developed a "self-perception theory" the basic tenet of which is that individuals come to know their internal attitude states by observing their own external behavior. "To the extent that information from internal cues is weak, ambiguous, or uninterpretable, the individual is functionally in the same position as an outside observer of his behavior" (Bem and McConnell, 1970, p. 23).

When respondents in the panel survey were asked in 1982 to recall their attitudes of nine years ago, clearly the most salient piece of externally available information that they possessed was their current attitudes as they had just described them to the interviewer. Consequently, we should expect that, as in the laboratory studies, panel respondents' recollections of their prior attitudes should be strongly biased toward their current ones. ${ }^{2}$ 
TABLE 4. Respondents' Recalled Change in Their Issue Positions from 1973 to 1982

\begin{tabular}{|c|c|c|c|}
\hline Issue & Correlation $^{a}$ & $\begin{array}{c}\text { Recall No } \\
\text { Change } \\
\text { (percentage) }\end{array}$ & $\begin{array}{c}\text { Recall Change of } \\
3+\text { Categories } \\
\text { (percentage) }\end{array}$ \\
\hline \multicolumn{4}{|c|}{ Parents } \\
\hline Guaranteed jobs & .83 & 78 & 4 \\
\hline Rights of accused & .78 & 70 & 8 \\
\hline Aid to minorities & .80 & 75 & 5 \\
\hline Legalize marijuana & .69 & 73 & 10 \\
\hline Women's roles & .80 & 69 & 10 \\
\hline Ideology & .80 & 70 & 2 \\
\hline \multicolumn{4}{|c|}{ Offspring } \\
\hline Guaranteed jobs & .47 & 46 & 14 \\
\hline Rights of accused & .60 & 50 & 15 \\
\hline Aid to minorities & .60 & 46 & 13 \\
\hline Legalize marijuana & .69 & 56 & 16 \\
\hline Women's roles & .54 & 50 & 23 \\
\hline Ideology & .45 & 38 & 10 \\
\hline
\end{tabular}

${ }^{a}$ Entries are Pearson product-moment correlations between 1982 stated issue position and 1982 recollection of 1973 issue position.

Table 4 provides resounding support for this expectation. In every instance, remembrances of past attitudes were more highly correlated with current self-placements than they were with the 1973 self-placements that the respondents were attempting to recall (compare the column of correlations in Table 4 with the one in Table 3). The percentage columns in Table 4 yield the same message as the correlations: substantially more respondents believed that their 1973 attitudes were identical to their current ones than could be corroborated by actually comparing their self-placements from 1973 with those from 1982 (contrast Table 4 with Table 2).

It could be argued that this result is not necessarily evidence of "cognitive heuristics" but rather of a desire on the part of respondents to appear cognitively consistent to the interviewers. That is, people might "know" that their attitudes have changed but, nevertheless, be reluctant to admit it for fear of appearing fickle or capricious in their political thinking. Perhaps, but this thesis cannot account for other features of the data that will be presented momentarily, nor does it explain why the tendency to recall past attitudes as being identical to current ones is so much stronger among the parents than among their offspring. Across the six self-placement items, 
an average of $73 \%$ of the older respondents maintained that their 1973 positions were no different from their more current ones. In contrast, only $48 \%$ of the offspring, on average, held that view (see Table 4). And this was despite the fact that younger respondents were not observably any less stable in their attitudes than were their elders, as was demonstrated in Table 2. How can this difference between the two age groups be explained?

One plausible explanation may be derived from Nisbett and Wilson's (1977) suggestion that apart from referencing current attitude states to infer past ones, individuals and external observers alike might employ certain "implicit causal theories" when attempting to reconstruct cognitive processes. These implicit causal theories may have any of several origins. For example, individuals growing up in a specific cultural or subcultural context may learn that certain stimuli "psychologically imply" a particular response, to use Abelson's (1968) phrase. With reference to the present case, respondents may have been using a causal heuristic that "younger people are less set in their ways than older people are."

Some support for this explanation is provided by responses to a question in the 1982 interview schedule. The question wording was: "Some people say that their basic political views change a lot as they get older. Others find that their basic political ideas don't change much. Thinking back over the past ten years or so, would you say that your basic political ideas have changed a great deal, somewhat, or hardly at all?" While $61 \%$ of the parental respondents chose the last option, only $36 \%$ of the offspring did. And, to reiterate, this was despite the fact that younger interviewees were not demonstrably less stable in their political attitudes than were their parents. The interpretation made here is that the reason younger respondents were less likely than their elders to recall their past policy and ideological positions as being identical to their current ones is because younger respondents believed they had just experienced a life stage of changing basic political views.

Taking the "implicit causal theories" idea one step further, Smith (1984) suggested that individuals may attempt to divine their past attitudes "from external clues such as known or perceived changes in national or community attitudes" (pp. 645-646). Applying this idea to the present case, our respondents may have relied on causal heuristics that correspond roughly to the aggregate profiles displayed previously in Table 1 . That is, they may have an intuitive sense that, generally, people have gotten more conservative on issues such as law and order or special treatment for minorities or that attitudes toward women's rights have gotten more liberal. The larger the observable population shift in an attitude has been, the more likely it is that such a heuristic would be available to individuals and, in turn, employed by them. If so, the panel data should show respondents' percep- 
TABLE 5. Relationships between Observed and Recalled Attitude Change on the Rights of Accused and Women's Roles Issues

A. Parents

\begin{tabular}{|c|c|c|c|c|c|}
\hline \multirow{2}{*}{ Issue } & \multirow{2}{*}{$\begin{array}{c}\text { Direction of } \\
\text { Observed Change }\end{array}$} & \multicolumn{3}{|c|}{ Direction of Recalled Change } & \multirow[b]{2}{*}{ Total } \\
\hline & & Liberal & None & Conservative & \\
\hline \multirow[t]{6}{*}{ a. Rights of Accused } & $3+$ Liberal & $15 \%$ & 80 & 5 & $100 \% \quad(61)$ \\
\hline & 1-2 Liberal & $7 \%$ & 70 & 23 & $100 \%(120)$ \\
\hline & None & $6 \%$ & 80 & 14 & $100 \%(172)$ \\
\hline & $1-2$ Conservative & $8 \%$ & 62 & 31 & $100 \%(182)$ \\
\hline & $3+$ Conservative & $3 \%$ & 67 & 30 & $100 \%(118)$ \\
\hline & Total & $7 \%$ & 71 & 22 & $100 \%(653)$ \\
\hline \multirow[t]{6}{*}{ b. Women's Roles } & $3+$ Liberal & $33 \%$ & 65 & 2 & $100 \%(160)$ \\
\hline & 1-2 Liberal & $31 \%$ & 66 & 3 & $100 \%(172)$ \\
\hline & None & $22 \%$ & 73 & 5 & $100 \%(241)$ \\
\hline & $1-2$ Conservative & $20 \%$ & 72 & 8 & $100 \%(100)$ \\
\hline & $3+$ Conservative & $18 \%$ & 73 & 9 & $100 \% \quad(56)$ \\
\hline & Total & $26 \%$ & 70 & 5 & $101 \%(729)$ \\
\hline
\end{tabular}

B. Offspring

\begin{tabular}{|c|c|c|c|c|c|}
\hline \multirow[b]{2}{*}{ Issue } & \multirow{2}{*}{$\begin{array}{c}\text { Direction of } \\
\text { Observed Change }\end{array}$} & \multicolumn{3}{|c|}{ Direction of Recalled Change } & \multirow[b]{2}{*}{ Total } \\
\hline & & Liberal & None & Conservative & \\
\hline \multirow{6}{*}{ a. Rights of Accused } & $3+$ Liberal & $33 \%$ & 53 & 14 & $100 \% \quad(36)$ \\
\hline & 1-2 Liberal & $17 \%$ & 59 & 24 & $100 \%(131)$ \\
\hline & None & $13 \%$ & 62 & 25 & $100 \%(189)$ \\
\hline & $1-2$ Conservative & $9 \%$ & 43 & 47 & $99 \%(289)$ \\
\hline & $3+$ Conservative & $5 \%$ & 42 & 53 & $100 \%(209)$ \\
\hline & Total & $11 \%$ & 50 & 39 & $100 \%(854)$ \\
\hline \multirow[t]{6}{*}{ b. Women's Roles } & $3+$ Liberal & $57 \%$ & 43 & 1 & $101 \%(159)$ \\
\hline & 1-2 Liberal & $53 \%$ & 44 & 3 & $100 \%(27$ \\
\hline & None & $34 \%$ & 62 & 5 & $101 \%(340)$ \\
\hline & $1-2$ Conservative & $40 \%$ & 39 & 22 & $101 \% \quad 8$ \\
\hline & $3+$ Conservative & $23 \%$ & 51 & 26 & $100 \% \quad(43)$ \\
\hline & Total & $44 \%$ & 50 & 6 & $100 \%(901)$ \\
\hline
\end{tabular}

tions of their own attitude shifts to be skewed in the direction of prevailing population trends independently of whether, for each individual, the observed attitude change actually corresponded to the national trend.

Precisely that pattern is found, as exemplified in Table 5. That table displays the relationships between observed and self-perceived attitude change in the form of simple contingency tables. Two issues with fairly 
TABLE 6. Relationships between Observed and Recalled Changes in Issue Positions

\begin{tabular}{|c|c|c|c|c|}
\hline $\begin{array}{l}\text { Issue for Which } \\
\text { There Is a Recalled } \\
\text { Change in Attitude }\end{array}$ & $\begin{array}{c}\text { Constant } \\
(a)\end{array}$ & $\begin{array}{l}\text { served Chan } \\
\text { Coefficient } \\
\quad(b)\end{array}$ & $R^{2}$ & $n$ \\
\hline \multicolumn{5}{|c|}{ Parents } \\
\hline Guaranteed jobs & $.02(.04)$ & $.09(.02)$ & .03 & 632 \\
\hline Rights of accused & $.28(.05)$ & $.11(.02)$ & .04 & 653 \\
\hline Aid to minorities & $.05(.04)$ & $.11(.02)$ & .05 & 702 \\
\hline Legalize marijuana & $-.25(.05)$ & $.20(.03)$ & .08 & 657 \\
\hline Women's roles & $-.41(.05)$ & $.11(.02)$ & .03 & 729 \\
\hline Ideology & $.18(.04)$ & $.18(.03)$ & .06 & 520 \\
\hline \multicolumn{5}{|c|}{ Offspring } \\
\hline Guaranteed jobs & $.20(.06)$ & $.31(.03)$ & .11 & 790 \\
\hline Rights of accused & $.30(.06)$ & $.26(.02)$ & .12 & 854 \\
\hline Aid to minorities & $.30(.05)$ & $.26(.03)$ & .09 & 866 \\
\hline Legalize marijuana & $-.23(.05)$ & $.35(.03)$ & .17 & 838 \\
\hline Women's roles & $-.76(.06)$ & $.28(.03)$ & .09 & 901 \\
\hline Ideology & $.16(.05)$ & $.61(.03)$ & .32 & 733 \\
\hline
\end{tabular}

Note. Entries are unstandardized ordinary least squares regression coefficients. Standard errors are in parentheses.

clear patterns (one a conservative bias and the other a liberal one) were selected: the rights of criminally accused and equal gender roles. The table shows that both parents and offspring with no observable change in attitudes toward defendents' rights were more likely to recall a conservative shift in their attitudes (i.e., one consistent with the population trend) than to recall a liberal shift. Indeed, even those respondents having an observed shift of one to two positions in the liberal direction were more likely to remember their opinion change as being conservative rather than liberal. This sort of pattern is even clearer (but in the opposite direction) with respect to self-placement on the gender roles continuum. In that instance, even those parental respondents whose observed attitude change was three or more steps in a conservative direction between 1973 and 1982 were more likely to perceive themselves as having changed in a liberal direction (the population trend) than in a rightward one.

A demonstration of comparable patterns with respect to other attitude domains, along with a summarization of the concomitant recall bias in the direction of current stated attitude, is accomplished in Table 6. That table is a bit more complicated than the others and deserves a word of explana- 
tion. It displays the results of a series of regressions of self-perceived attitude change on externally observed attitude change. The dependent variable, self-perceived attitude change, is operationalized as the difference between a respondent's 1982 self-placement on a particular opinion scale and the respondent's 1982 recollection of his or her 1973 opinion scale position. The independent variable, observed attitude change, is simply the difference between a respondent's self-placements as reported in 1982 and 1973 . The regression equation is the following:

$$
\left(S_{82}-R_{73}\right)_{i}=a+b\left(S_{82}-S_{73}\right)_{i}+u_{i}
$$

As can be seen from inspection of Equation 1, the $b$ coefficient measures the overall extent to which each one point difference between a respondent's positions on an issue as stated in 1973 and 1982 is translated into an attitude shift as recalled by that respondent in 1982 . Values of $b$ between zero and one would indicate that respondents on the whole believed that their attitudes had changed less than may be observed in their stated issue positions of 1973 and 1982 . Values greater than unity would imply that individuals tended to have an exaggerated sense of how much they changed issue positions from 1973 to 1982 . The constant term, $a$, indicates the magnitude of any net directional bias in respondents' remembrances of their attitude evolution over the study period. A positive value denotes a conservative bias, ceteris paribus; that is, on average individuals with no observed difference in stated opinions from 1973 to 1982 recalled that they had become more conservative since 1973 by an amount of $a$ units. A negative $a$ value has a similar interpretation but in the liberal direction.

The $b$ coefficients in Table 6 show that, for the parental cohort, recalled attitude change was almost independent of observed attitude change: on average, an observed shift in self-placement of one position on a 7-position scale translated into a one-tenth to two-tenths of a position self-perceived shift for that cohort. This means that to the extent parents' recollections of their 1973 attitudes corresponded at all to those attitudes as stated originally, it was because of whatever resemblance existed between their current dispositions and their prior ones. For the younger cohort, the relationships between self-perceived and observed attitude shifts were a bit greater, but even so, a one point observable change led to only about a one-third point recalled change with respect to the five policy domains. Only on ideological self-concept for the younger respondents was the correspondence between observed and self-perceived change impressive.

The fact that this correspondence occurred for ideological orientation rather than for policy preferences is not entirely surprising. As a number of recent studies have pointed out, the notion of an individual's ideological 
self-concept is closely related to the cognitive psychologists' concept of a political self-schema (Conover and Feldman, 1984; Lau, 1984; Hamill and Lodge, 1984). Self-schemata can be thought of as "generalizations or theories about the self in particular domains, derived from past experience, that are used to guide the processing of social information relevant to these domains" (Markus and Zajonc, 1985). H. Markus and her colleagues have investigated a variety of cognitive consequences associated with self-schemata and have concluded that "schematics," i.e., persons possessing a schema in a particular domain, have better recognition memory and recall for information relevant to that domain than do "aschematics" (Markus and Sentis, 1982; Markus et al., 1982). It makes sense, then, that the evolution of one's ideological self-concept would be more likely to be recalled reliably than would one's predispositions on various policy matters.

What is more puzzling is the substantial contrast between younger citizens and their parents in terms of the reliability of self-perceptions of past ideological orientations. Additional analysis shows that part of the difference is due to the younger cohort's higher overall level of education, a factor that accounts for the consistently larger $b$ coefficients for that cohort as compared with comparable values obtained for the parent sample. Although higher education is not a guarantee of increased political sophistication (and a consequently stronger ideological self-schema), the two are clearly related. Even so, with education level held constant the correspondence between observed and recalled change in ideological self-concept remained noticeably greater among the offspring as compared with their elders. Controlling for other plausible variables, e.g., amount of stated interest in politics or degree of attendance to political information in the media, also failed to erase the between-cohort difference. Although it must be made tentatively at this time, the conclusion is that we are observing a generational distinction in the extent to which ideologically tinged information is relevant to and reflected in political self-schemata.

These results prompted one other attempt to assess the hypothesis that schematics are more likely than aschematics to recall schema-relevant information. One section of the 1982 interview schedule elicited respondents' evaluations of various social and political groups, including the women's liberation movement, by use of a 0-100 degree "feeling thermometer" scale. Using these ratings to classify respondents, it was found that persons who felt "very warm or favorable" (100-degree rating) toward the women's liberation movement - and who presumably possessed unambiguous "feminist" schemata - were substantially more accurate in recalling their 1973 positions on the gender roles item than were respondents who stated that they had "no feeling at all" (50 degrees) or else did not know anything concerning the women's liberation movement. For the younger cohort, 
$56 \%$ of the feminist schematics recalled their 1973 positions accurately as compared with only $33 \%$ of the aschematics $\left(\chi^{2}=10.13, p<.01\right)$. Among the parents, the corresponding values were $44 \%$ for schematics versus $28 \%$ for aschematics $\left(\chi^{2}=5.87, p=.05\right)$.

Results from another study based on these panel data (Jennings, 1984) also support the contention that individuals for whom politics is relevant to their self-schemata are more likely to recall accurately their policy opinions than are persons who are politically aschematic. Focusing exclusively on the baby-boom cohort, Jennings found that respondents who had reported participating in political protests while in college had "a more accurate mental picture of their political transitions than did the non-protesters" (p. 46).

Returning to Table 6 , recall that the columns of $a$ values in that table speak to the hypothesis that self-perceptions of one's attitude shifts may be skewed in the direction of population trends. As can be seen in Table 6, the magnitudes and signs of estimated $a$ values are consistent with this idea. With one exception, $a$ coefficients for issues on which the population trend was in a conservative direction have positive signs, indicating a conservative bias in recall, while the $a$ values for the gender role item (the only one having a liberal trend) are negative and fairly large.

\section{"Explaining" Self-Perceived Attitude Change}

We have seen that, with some noted exceptions, individuals' remembrances of their changing political opinions do not comport well with observed changes in those opinions. This fact notwithstanding, some experimental results suggest that individuals are quite talented at constructing plausible-sounding - but quite possibly erroneous - "explanations" for their self-perceived attitude evolution. Consider, for example, Wixon and Laird's (1976) comments about the subjects in their experiments in which attitude change was induced by having participants give a counterattitudinal speech:

For any of the items which had any suggestion of political content, the common explanation for these subjects (run during the fall of 1974) was that "Watergate had changed my mind about that." Subjects are characteristically so persuasive when offering these explanations that we would be seriously tempted to believe them except that no corresponding changes occur in control groups. These observations suggest that these subjects were, in effect, revising their own histories to make sense of the change in their attitudes. The speed, magnitude, and certainty of these revisions were striking. (p. 383)

As in the Wixon-Laird research, respondents in our panel study who 
thought that their policy opinions had changed from 1973 to 1982 were invited to provide their own reasoning about why the change occurred. Unlike the experiment, we cannot know the true source of respondents' attitude changes. We can, however, determine the extent to which respondents were willing to supply explanations for their self-perce ved opinion shifts, even when those self-perceptions were in disaccord with their observed attitude history. In addition, we may explore the content of these autobiographical explanations to determine what regularities they may display.

The first topic can be dealt with quickly. Regardless of whether selfperceived and observed attitude change concurred, nearly all respondents who thought that their opinions on some policy matter had changed also had ideas about why the change had occurred. Even in instances where the recalled opinion shift ran directly counter to the observed one, no more than $5 \%$ to $10 \%$ of the respondents failed to supply a supporting story for their recollections. ${ }^{3}$

Respondents were almost certainly not deliberately trying to deceive the interviewers. Rather, the conclusion drawn here is that respondents were simply searching their memories for some historical or autobiographical circumstance that could plausibly account for the self-perceived opinion change-much as an external observer possessing the same information would.

Not only was the ability to provide "explanations" for self-perceived attitude shifts independent of the correspondence between perceived and observed shifts, so was the content of those explanations. Respondents' comments regarding their recalled attitude evolutions were categorized according to whether they were references to specific events in one's own life, mentions of political or societal events, general references to "aging," miscellaneous issue-specific remarks, and so on. The distributions of comments across a 6 -category coding scheme were virtually the same regardless of whether or not perceived and observed opinion change coincided.

Table 7 summarizes the kinds of explanations provided by respondents for their self-perceived attitude shifts in the various issue areas. For both cohorts, there was a clear tendency for comments to revolve around references to various political or social events, circumstances, or situations that occurred between 1973 and 1982.

For example, one parent accounted for her self-perceived rightward drift on federal jobs programs this way:

The economy was different [in 1973]. Unemployment was low, and when the economy is good you feel that the government should give everyone help.

A younger male observed that he had probably become more conservative 
TABLE 7. Reasons Given for Recalled Attitude Change (Percentages)

\begin{tabular}{|c|c|c|c|c|c|c|c|}
\hline Issue & $\begin{array}{l}\text { Aging } \\
(\%)^{a}\end{array}$ & $\begin{array}{c}\text { Specific } \\
\text { Life } \\
\text { Events } \\
(\%)\end{array}$ & $\begin{array}{c}\text { Broad } \\
\text { Personal } \\
\text { Outlook } \\
(\%)\end{array}$ & $\begin{array}{c}\text { Political } \\
\text { Social } \\
\text { Events } \\
(\%)\end{array}$ & $\begin{array}{c}\text { Misc. } \\
\text { Issue } \\
\text { Specific } \\
(\%)\end{array}$ & $\begin{array}{c}\text { No } \\
\text { Content } \\
\text { Don't } \\
\text { Know } \\
(\%)\end{array}$ & $\begin{array}{c}\text { Total } \\
n\end{array}$ \\
\hline \multicolumn{8}{|c|}{ Parents } \\
\hline Guaranteed jobs & 9 & 12 & 9 & 72 & 6 & 21 & 186 \\
\hline Rights of accused & 3 & 7 & 4 & 91 & 9 & 15 & 234 \\
\hline Aid to minorities & 6 & 7 & 7 & 89 & 16 & 19 & 195 \\
\hline Legalize marijuana & 0 & 8 & 3 & 88 & 24 & 8 & 226 \\
\hline Women's roles & 4 & 23 & 3 & 77 & 16 & 7 & 244 \\
\hline Ideology & 17 & 8 & 27 & 51 & 9 & 22 & 192 \\
\hline \multicolumn{8}{|c|}{ Offspring } \\
\hline Guaranteed jobs & 7 & 28 & 20 & 57 & 9 & 15 & 510 \\
\hline Rights of accused & 3 & 20 & 10 & 72 & 17 & 10 & 475 \\
\hline Aid to minorities & 2 & 18 & 13 & 72 & 12 & 14 & 517 \\
\hline Legalize marijuana & 3 & 20 & 6 & 70 & 18 & 11 & 422 \\
\hline Women's roles & 3 & 40 & 12 & 54 & 11 & 11 & 481 \\
\hline Ideology & 14 & 19 & 44 & 27 & 10 & 20 & 523 \\
\hline
\end{tabular}

"Entries sum to more than $100 \%$ since interviewers recorded up to two responses per issue area.

with respect to federal programs for minority groups for the following reason:

Government programs to do this kind of thing have been terrible failures. Money ends up lining the pockets of politicians.

This emphasis on situational factors is consistent with the Jones and Nisbett (1971) hypothesis that observers of events are prone to attribute responsibility for outcomes to persons rather than to situations, whereas actors in events will tend to do just the reverse. That is because, for an observer, "the actor ... is dynamic and interesting, while situations more commonly are static and pallid. . . . The actor and his actions, in other words, are 'figural' against the 'ground' of the situation" (pp. 1222-1223). Actors themselves, in contrast, cannot easily watch themselves act - their dispositions are not "figural" to them. Consequently, actors (our respondents with respect to their own attitudes and behaviors) tend to refer to situational factors in their attributions of cause.

Despite the overall emphasis on situational factors, respondents did mention other things. In particular, Table 7 shows that baby-boomers were noticeably more likely than their parents to be introspective in their comments, referring to their own aging, to specific events or experiences in 
their own lives, or to changes in their own broad personal outlooks. For instance, one younger woman thought that she had come to be a strong supporter of equal gender roles because of her experiences in the work force:

Maybe because I've worked, and I know what it's like to do a man's job and not get paid for it.

Finally, and in keeping with aforementioned generational distinctions in the salience of ideological concepts to self-schema, Table 7 indicates that younger respondents were substantially more likely than their elders to see any self-perceived ideological evolution over the 9 -year period as being one aspect of a larger process of development in their broad personal outlooks, that is, as part of acquiring a richer, more mature perspective on life. For instance, a 34-year-old woman from Salt Lake City elaborated her belief that she had become less conservative over the past 9 years:

I've grown a lot. I know more now. By "conservative" I mean I was immature, shy, and didn't know much about life. Then I learned I had to voice my opinion and stand up for my rights or else nobody would care.

A similar kind of explanation, but a self-perceived ideological evolution in the opposite direction, was provided by a 35-year-old Nebraskan:

I was not well-informed philosophically or socially at that time. I tended to be a little unforgiving in 1973. Now I believe I can be more tolerant due to my better understanding of things.

\section{CONCLUSIONS}

An analysis of the policy preferences of the baby-boom generation and its parents revealed a marked conservative shift between 1973 and 1982 for the former group and a weaker conservative trend for the latter - weaker primarily because the parents were, on the whole, fairly conservative to begin with. The one exception to this pattern concerned attitudes toward the roles of women in society, for which both cohorts exhibited a distinct liberalization of opinion. Overall, the younger cohort remained more liberal on all issues than that of their parents, but the generation gap had narrowed considerably by 1982 . With respect to the individual-level attitude movements that lay beneath the aggregate trends, we found only modest degrees of observed attitude stability, particularly for opinions in domains that were abstract and not very salient to everyday experience.

The bulk of the study focused on individuals" recollections of their past attitudes. Those recollections tended to correspond poorly to attitudes as 
originally expressed, and respondents generally perceived that they were more stable attitudinally than was indicated observationally. When attempting to reconstruct their past political orientations, respondents appeared to rely on the kinds of simple "rules of thumb" that one would use to account for another's behavior. One such rule appeared to be that young adulthood is a time of greater attitude change than is middle or old age. Another rule involved inferring one's own attitude evolution from knowledge about population trends. Finally, individuals were capable of supplying "explanations" of their self-perceived opinion shifts even when those perceptions were directly contrary to their observed opinion changes. Generally, those explanations focused on well-known political, societal, or historical events, a pattern consistent with some hypotheses arising from experimental research. Taken together, these results indicate that policy orientations generally do not have strong internal cognitive representations, are eminently changeable, and that, once those orientations are changed, an individual's cognitive autobiography is rewritten so as to render the changes invisible.

Of course, not all individuals are equally unaware of their attitude histories. There was evidence that members of the Vietnam-era cohort who possessed ideological self-schemata tended to recall accurately any changes in those schemata and interpreted such change as part of a larger process of development in their broad personal outlooks. Similarly, individuals who felt very favorably toward the women's liberation movement, and for whom feminist issues were likely to be schema-relevant, were substantially more reliable in recollecting their past attitudes on the issue of equal gender roles than were persons who were ostensibly aschematic with respect to such matters. So, too, were former political protesters more likely than nonprotesters to recall their past political attitudes reliably.

These findings suggest that the reliability of recall of past attitude states varies with the degree to which cues about those past states are cognitively available to the individual. For those persons whose policy preferences are integral to their views of themselves, cues about prior policy attitudes will be cognitively available and recall of such attitudes will be reliable. For most people, though, vivid, informative clues to one's past policy opinions probably do not come readily to mind, and recollections of those opinions will be guided by the kinds of "rules of thumb" described above.

Finally, there is the matter of measurement error in survey responses. Achen (1975), Pierce and Rose (1974), Dalton (1980), and others have argued that the typically weak correlations of attitudes as measured across waves of panel surveys, and the low coherence of individual survey responses in general, are due largely to shortcomings in measurement procedures rather than to "nonattitudes." Measurement error surely exists in the data on which the present study was based. Can it be that the patterns 
found herein can be dismissed as mere artifacts of such error?

Measurement noise not only can but probably does play a role in accounting for some of the results displayed here. For example, some of the discrepancy between observed attitudes in 1973 and 1982 is undoubtedly due to measurement imprecision, as is part of the slippage between recalled and originally stated self-placements. It is doubtful, however, that the findings reported here are entirely artifactual.

Recall, for example, that older respondents' remembrances of their 1973 issue positions were virtually independent of those positions as originally registered in the 1973 surveys, ceteris paribus. But the same measurement techniques produced autocorrelations of contemporary political attitudes from 1973 to 1982 that were regularly in the .4 to .6 range. Consequently measurement error alone cannot account for the prevailing political amnesia. In addition, the evidence for the existence of implicit causal heuristics, the distinctions between younger and older cohorts' recollections and rationalizations of attitude change, or differences in the recollective reliability of politically schematic versus aschematic persons probably cannot be explained parsimoniously by reference solely to measurement problems. These kinds of effects, uncovered originally in the laboratory and confirmed and elaborated here, are, I conclude, both real and robust.

Acknowledgments. Support for this study was provided by a grant from the National Institute on Aging of the National Institutes of Health. An earlier version of this report was prepared for the 19th Annual Carnegie Symposium on Cognition, Carnegie-Mellon University, May 18-20, 1984. The author is grateful to Donald R. Kinder and M. Kent Jennings for their guidance, criticism, and friendship.

\section{NOTES}

1. See Markus and Jennings (1985) for further discussion of this topic.

2. There is an alternative theory, compatible with the Bemian one, that also predicts that respondents' reports of their past scale locations would be biased toward their current ones. Tversky and Kahneman (1974) have demonstrated convincingly that an "anchoring" effect occurs in situations wherein individuals are required to make a numerical estimate by starting from some initial value that is adjusted to yield a final answer. These final answers typically fail to depart sufficiently from the starting values (see also Slovic and Lichtenstein, 1971). In the 1982 panel interviews, respondents were asked first to state their current locations on an attitude scale and then to provide estimates of what their positions were in 1973. If the anchoring tendency affects these estimates, respondents' perceived amounts of attitude change would be systematically smaller than the observed differences between their 1982 self-placements and those provided in 1973.

3. Instances in which observed and recalled opinion shifts directly conflicted were hardly rare-see Table 5. 


\section{REFERENCES}

Achen, C. H. (1975). Mass political attitudes and the survey response. American Political Science Review 69: 1218-1231.

Bem, D. J. (1972). Self-perception theory. In L. Berkowitz (ed.), Advances in Experimental Social Psychology, Vol. 6. New York: Academic Press.

Bem, D. J., and McConnell, K. H. (1970). Testing the self-perception explanation of dissonance phenomena: On the salience of premanipulation attitudes. Journal of Personality and Social Psychology 14: 23-31.

Converse, P. E. (1964). The nature of belief systems in mass publics. In David E. Apter (ed.), Ideology and Discontent, pp. 206-261. Glencoe: Free Press.

Converse, P. E. (1970). Attitudes and non-attitudes: Continuation of a dialogue. In Edward R. Tufte (ed.), The Quantitative Analysis of Social Problems, pp. 168-189. Reading, Mass.: Addison-Wesley.

Converse, P. E., and Markus, G. B. (1979). Plus ca change . . .: The new CPS Election Study Panel. American Political Science Review (February) 73: 32-49.

Conover, P. J., and Feldman, S. (1984). How people organize the political world: A schematic model. American Journal of Political Science 28: 95-126.

Dalton, R. J. (1980). Reassessing parental socialization: Indicator unreliability versus generational transfer. American Political Science Review 74: 421-431.

Fagen, R. R. (1970). Cuba: The political content of adult education. In R. S. Sigel (ed.), Learning About Politics. New York: Random House. (Original work published 1964, Stanford: The Hoover Institution on War, Revolution, and Peace.)

Fiske, S. T., and Taylor, S. E. (1984). Social Cognition. Reading, Mass.: AddisonWesley.

Goethals, G. R., and Reckman, R. F. (1973). The perception of consistency in attitudes. Journal of Experimental Social Psychology 9: 491-501.

Greenwald, A. G. (1980). The totalitarian ego: Fabrication and revision of personal history. American Psychologist 35: 603-618.

Hamill, R., and Lodge, M. (1984). Cognitive consequences of political sophistication. Paper presented at the 19th Annual Carnegie Symposium on Cognition, Carnegie-Mellon University.

Jennings, M. K. (1984). Residues of a movement: The aging of the American protest generation. Paper presented at conference sponsored by the Social Science Research Institute at Cadenabbia, Italy.

Jennings, M. K., and Markus, G. B. (1984). Partisan orientations over the long haul: Results from the three-wave political socialization panel study. American Political Science Review 78; 1000-1018.

Jennings, M. K., and Niemi, R. G. (1974). The Political Character of Adolescence. Princeton: Princeton University Press.

Jennings, M. K., and Niemi, R. G. (1981). Generations and Politics. Princeton: Princeton University Press.

Jones, E. E., and Nisbett, R. E. (1971). The Actor and the Observer: Divergent Perceptions of the Causes of Behavior. Morristown, N.J.: General Learning Press.

Kinder, D. R., and Sears, D. O. (1985). Public opinion and political action. In G. Lindzey and E. Aronson (eds.), The Handbook of Social Psychology (3rd ed.), chap. 25. New York: Random House.

Lau, R. (1984). Political schemas, candidate evaluations, and voting behavior. Paper presented at the 19th Annual Carnegie Symposium on Cognition, Carnegie-Mellon University. 
Markus, G. B., and Jennings, M. K. (1985). Of Yuppies, Enddies, and the formation of political generations. Paper presented at the annual meetings of the American Political Science Association, New Orleans.

Markus, H., Crane, M., Bernstein, S., and Siladi, M. (1982). Self-schemas and gender. Journal of Personality and Social Psychology 42: 38-50.

Markus, H., and Sentis, K. (1982). The self in social information processing. In J. Suls (ed.), Social Psychological Perspectives on the Self. Hillsdale, N.J.: Lawrence Erlbaum Publishing.

Markus, H., and Zajonc, R. B. (1985). The cognitive perspective in social psychology. In G. Lindzey and E. Aronson (eds.), The Handbook of Social Psychology (3rd ed.), chap. 4. New York: Random House.

Moss, L., and Goldstein, H. (eds.) (1979). The Recall Method in Social Surveys. London: University of London Institute of Education.

Nisbett, R. E., and Wilson, T. D. (1977). Telling more than we can know: Verbal reports on mental processes. Psychological Review 84: 231-259.

Page, B. I., and Shapiro, R. Y. (1983). Effects of public opinion on policy. American Political Science Review 77: 175-190.

Pierce, J. C., and Rose, D. (1974). Nonattitudes and American public opinion: Examination of a thesis. American Political Science Review 68: 626-649.

Slovic, P., and Lichtenstein, S. (1971). Comparison of Bayesian and regression approaches to the study of information processing in judgment. Organizational Behavior and Human Performance 6: 649-744.

Smith, T. W. (1984). Recalling attitudes: An analysis of retrospective questions on the 1982 GSS. Public Opinion Quarterly 48: 639 649.

Smith, T. W., and Klaeser, D. L. (1983). Looking backwards: A summary of findings and recommendations. Historical Methods 16: 16-29.

Tversky, A., and Kahneman, D. (1974). Judgment under uncertainty: Heuristics and biases. Science 185: 1124-1131.

Wixon, P. R., and Laird, J. D. (1976). Awareness and attitude change in the forced-compliance paradigm: The importance of when. Journal of Personality and Social Psychology 34: 376-384. 